\title{
Determinantes da Formação de Board Interlocking no Mercado de Capitais Brasileiro
}

\section{Resumo:}

Este artigo tem como objetivo identificar os principais determinantes da formação de Board Interlocking no mercado de capitais brasileiro. Como estrutura teórica, utiliza a teoria da Agência e Governança Corporativa, teoria da Dependência dos Recursos e Conselho de Administração e a Caracterização do Board Interlocking. A amostra compreende 58 empresas brasileiras que participam do Índice Bovespa (Ibovespa). O estudo classifica-se como empírico-analítico. Em relação aos objetivos, caracteriza-se como exploratória e quanto aos procedimentos, trata-se de uma pesquisa documental. Os dados sobre os Conselhos de Administração foram coletados nos Formulários de Referência, disponibilizados no website da Bolsa de Valores de São Paulo (BM\&FBOVESPA). Os resultados encontrados demonstram que a presença de Board Interlocking é generalizada nessas empresas e, normalmente, está associada a quatro fatores: (1) formação do grupo econômico; (2) controle governamental; (3) formação de fundos de pensão; e (4) presença de profissionais com reconhecida experiência de mercado. Os resultados também sugerem que os três primeiros fatores originam ligações mais duradouras e dificilmente tais conexões são rompidas. Por outro lado, as ligações realizadas por meio de profissionais com experiência de mercado tendem a ser mais instáveis por ser a presença de tais profissionais muito requisitada no conselho de diferentes companhias.

Palavras-chave: Board Interlocking; Conselho de Administração; mercado de capitais brasileiro; Bovespa. Redes sociais.
Flávio Ribeiro

Mestre pela Universidade Federal do Paraná (UFPR).

Professor Assistente na Universidade Estadual do Centro-Oeste (Unicentro) Campus de Irati.

Contato: PR 153 Km 7. Riozinho. Irati-PR. CEP: $84500-000$.

E-mail: flavioribeiro@irati.unicentro.br

Romualdo Douglas Colauto

Doutorado pela Universidade Federal de Santa Catarina (UFSC).

Professor Associado II na Universidade Federal do Paraná (UFPR).

Contato: Av. prof. Lothário Meissner, n. ${ }^{0}$ 632 sala 19. Jardim Botânico. Curitiba-PR. CEP: 80210-170.

E-mail: rdcolauto.ufpr@gmail.com

\section{Ademir Clemente}

Pós-doutorado pela Universidade de Londres.

Professor Associado VII na Universidade Federal do Paraná (UFPR).

Contato: Av. prof. Lothário Meissner, n. ${ }^{0}$ 632. Jardim Botânico. Curitiba-PR. CEP: 80210-170.

E-mail: ademir@ufpr.br 


\section{Introdução}

A formação de Board Interlocking está associada às conexões financeiras da organização e à existência de grupos econômicos (Dooley, 1969). No entanto, Schoorman, Bazerman e Atkin (1981), Hillman, Cannella e Paetzold (2000) e Barringer e Harrison (2000) sugerem que a presença de profissionais em diferentes conselhos de administração está atrelada à troca de conhecimento e expertise que os profissionais fornecem para a companhia e ao favorecimento da imagem no mercado. O crescimento das organizações e o desenvolvimento da economia mundial foram determinantes para a separação entre propriedade e controle nas empresas modernas. O controle individual até antes dominante tornou-se inviável. Para maximizar suas riquezas, os investidores viram-se obrigados a contratar pessoas especializadas para administrar suas organizações.

Com a pulverização do capital, o poder dos gestores foi fortalecido, permitindo autonomia e decisões alinhadas aos seus próprios interesses. Esse fortalecimento desencadeou problemas, uma vez que algumas decisões dos gestores passaram a não estar necessariamente coerentes com os interesses dos acionistas. A necessidade de controlar os interesses diferentes convergiu para a criação de conselhos de administração. O principal papel do Conselho de Administração consiste em monitorar os conflitos entre agentes (Fama \& Jensen, 1983). Porém, nos últimos anos, a teoria da Dependência de Recursos (Pfeffer, 1972, Pferffer \& Salancik, 1978) tem destacado a utilização dos profissionais do conselho como meio de ligação entre as empresas, fenômeno conhecido como Board Interlocking. Tais ligações são fontes de importantes recursos para a empresa, mas também podem tornar-se canais para disseminação de práticas corporativas, como o gerenciamento de resultado, por exemplo.

Os estudos sobre conselhos de administração têm-se concentrado em duas principais linhas teóricas: i) teoria da Agência (Fama \& Jensen, 1983) e ii) teoria da Dependência de Recursos (Pfeffer, 1972; Johnson, Daily \& Ellstrand, 1996). A teoria da Agência atribui ao Conselho de Administração o papel de controlar e monitorar as decisões tomadas pelos gestores, minimizando o conflito de interesse entre as partes da organização (Fama \& Jensen, 1983). A maioria dos estudos sobre conselho de administração tem por base a teoria da Agência (Hillman \& Dalziel, 2003). Todavia, a complexidade dos ambientes corporativos tem limitado a aplicação dessa teoria, por não ser capaz de explicar alguns fenômenos sociais relacionados ao conselho (Eisenhardt, 1989).

A teoria da Dependência de Recursos busca suprir essa lacuna deixada pela teoria da Agência. Na ótica da teoria da Dependência de Recursos, o conselho de administração age como redutor das incertezas no ambiente corporativo, estabelecendo ligação com outras empresas por meio dos seus conselheiros, buscando, dessa forma, a captação de recursos necessários para o desenvolvimento da organização (Pfeffer, 1972, Pfeffer \& Salancik, 1978).

A redução da incerteza do ambiente pode ser administrada pela organização, empregando determinadas estratégias (Pfeffer, 1972). A relação entre a firma e o ambiente é um processo de troca (Camilo, Marcon \& Bandeira-de-Mello, 2012), em que a organização, para se promover, necessita de recursos vitais, que são obtidos pela interação com o ambiente. Essa interação é uma forma de responder aos fatores de competitividade, melhorando o desempenho (Pearce, 1983).

A presença de um conselheiro no conselho de administração de outra empresa caracteriza um fenômeno conhecido internacionalmente como Board Interlocking (Knowles, 1973). Assim, entende-se que esse fenômeno ocorre quando um conselheiro de uma companhia exerce o mesmo cargo no conselho de administração de outra. Board Interlocking é um fenômeno importante no contexto organizacional (Fontes Filho \& Leal, 2012). Por meio dele, as empresas conseguem importantes recursos, como acesso a parceiros comerciais e conhecimentos específicos (Gales \& Ksner, 1994). Nesse contexto, o presente artigo pretende responder à seguinte questão: Quais os determinantes da formação do Board Interlocking para empresas do mercado de capitais brasileiro? 
O artigo busca identificar os principais determinantes para a formação do Board Interlocking no mercado de capitais brasileiro. Para isso, procura-se contemplar os aspectos organizacionais que influenciam a formação de laços corporativos entre as organizações e, especificamente, considera o fenômeno de Board Interlocking. Ressalta-se que são escassos os estudos sobre Board Interlocking encontrados na economia brasileira. Dessa forma, abre-se a possibilidade de o presente artigo despertar o interesse pela temática e oportunizar a apropriada discussão teórica e os correspondentes estudos empíricos no campo de pesquisa em Contabilidade Financeira e Finanças Corporativas.

\section{Teoria de Agência e Governança Corporativa}

Adam Smith, no século XVIII, fomentou a discussão sobre a separação da propriedade e o controle, tema estudado posteriormente na literatura financeira sobre a estrutura de Governança Corporativa. Na obra, The Wealth of Nations, Smith (1776) demonstrou preocupação com a separação entre propriedade e controle nas organizações e destacou a displicência dos gestores em relação ao dinheiro dos investidores. As características organizacionais da época não permitiram que essa proposição fosse comprovada empiricamente.

Passado um longo período, Berle e Means (1932), no texto The Modern Corporation and Private Property, reacenderam a discussão sobre a separação de propriedade e controle. Para Iudícibus e Lopes (2004), esse trabalho foi fundamental para introduzir as bases essenciais para compreensão do conflito de agência entre o acionista e o executivo. Berle e Means (1932) observaram que, com o crescimento das organizações, elas não poderiam mais ser controladas por uma única pessoa ou por uma única família. Demonstrou que a divisão de controle tornara-se necessária, a fim de maximizar a riqueza organizacional. A pulverização de controle fortaleceu o poder dos administradores, permitindo que possuíssem autonomia nas decisões e passassem a agir em função de seus próprios interesses. O estudo de Berle e Means (1932) forneceu evidências empíricas sobre a concentração de propriedade, mas a ausência de obrigatoriedade das empresas em publicar suas demonstrações foi um importante limitador dos resultados.

Problemas decorrentes da separação de propriedade e controle nas organizações estão relacionados com um dos paradigmas teóricos mais importantes na literatura contábil, a teoria da Agência (Lambert, 2001). A teoria da Agência tem ajudado, desde então, a explicar os conflitos entre os gestores e acionistas majoritários e entre esses últimos e os acionistas minoritários. Os estudos de Spence e Zeckhauser (1971) e Ross (1973) destacam-se por serem dos primeiros a evidenciar a teoria da Agência. Ambos os trabalhos tiveram como base a análise da estrutura de remuneração variada dos executivos.

A relação de agência pode ser definida "como um contrato em que uma ou mais pessoas (o principal) emprega outra pessoa (o agente) para realizar um serviço ou trabalho em seu favor, envolvendo a delegação de alguma autoridade" (Jensen \& Meckling, 1976, p. 310). Os autores postulam que o contrato entre o acionista e o executivo é permeado por uma relação de agentes, em que o primeiro é visto como principal e o segundo como agente. Se ambas as partes agirem de forma a maximizar suas riquezas, é coerente acreditar que o agente nem sempre agirá em razão do interesse do principal. Essa distinção entre o comportamento do principal e do agente é a premissa fundamental que transpassa a teoria da Agência. Em 1994, no artigo “The nature of man", Jensen e Meckling (1976) discutiram o comportamento humano, contemplando a ideia da impossibilidade de um indivíduo priorizar a maximização da riqueza de outra pessoa em detrimento de sua própria. Dessa forma, cria-se um ambiente para fundamentar a hipótese principal da teoria da Agência: a inexistência de agente perfeito (Okimura, 2003). Essa hipótese abre lacunas para a divergência entre o comportamento esperado pelo principal e o realmente manifestado pelo agente. 
Iudícibus e Lopes (2004) afirmam que o conflito de agência surge quando agentes possuem interesses divergentes do principal e, ao colocarem seus interesses pessoais em primeiro plano acabam prejudicando o funcionamento das organizações. De acordo com essa visão, o acionista deve se proteger contra a tentativa de expropriação pelo administrador. Essa expropriação pode acontecer por intermédio de uma simples apropriação indevida de um ativo ou até mesmo por formas mais sofisticadas, como a realização de investimentos com retorno duvidoso, aumentando o poder do gestor na organização e reduzindo a parcela de dividendos a distribuir.

Para Barney e Hesterly (2004), a transferência de poder do proprietário para o executivo pode tornar-se problemática por três motivos: i) a divergência de interesses que normalmente ocorre entre o principal e o agente; ii) os custos inerentes ao monitoramento das ações do agente; e iii) os custos incidentes para obtenção de informações disponíveis ao agente ou em seu poder. Os custos de monitorar perfeitamente a ação do gestor estão relacionados com a assimetria de informação, já que, por inúmeras vezes, os gestores possuem um nível de informação muito superior ao dos investidores.

Estudos recentes envolvendo conflitos de agência convergem para problemas gerados por informações incompletas, situação na qual nem todos os participantes da organização possuem o mesmo nível de informação. Esse fenômeno é conhecido na literatura financeira como assimetria informacional (Hendriksen \& Van Breda, 2007). Para Copeland, Weston e Shastri (2005), a assimetria de informação não pode ser entendida como um evento, mas, sim, como um processo inerente à existência de diferentes níveis de conhecimento entre as partes que negociam.

Para Pratt e Zeckhauser (1985), dificilmente as informações disponíveis são completas. Essa imperfeição informacional faz com que o principal estabeleça contratos com o agente para que seus interesses sejam respeitados. O comportamento de dependência entre indivíduos ocasiona problemas de agência. Portanto, torna-se interessante identificar o nível de assimetria informacional, uma vez que a capacidade de observar o ambiente é limitada. Caso isso não ocorresse, a informação seria transparente e não existiriam problemas de agência (Segatto-Mendes, 2001).

Exemplos práticos de problemas de conflito de interesse e assimetria informacional foram observados desde o final do Século XX, em função de escândalos empresariais, especialmente nos Estados Unidos. As histórias das gigantes americanas, Enron, WorldCom e Tyco foram determinantes para que entidades governamentais repensassem novas formas de controlar os poderes dos executivos (Guerra, 2009). A existência de problemas de agência e diferentes níveis de conhecimento entre os investidores e gestores foram decisivos para a criação de um conjunto de mecanismos internos e externos para harmonizar a relação de interesses entre o principal e o agente. Para tal conjunto de mecanismos, deu-se o nome de Governança Corporativa (Silveira, Barros \& Famá, 2003).

A partir da década de 90, o termo Governança tornou-se disseminado ao público em geral (Carlsson, 2001). Para Shleifer e Vishny (1997), a Governança Corporativa pode ser definida como um conjunto de mecanismos pelos quais o investidor garante a obtenção do retorno de seu investimento. De forma mais detalhada, a Organization for Economic Co-operation and Development (Oecd, 2004) define a Governança Corporativa como um conjunto de relacionamentos entre investidores, executivos, conselheiros e demais partes interessadas, fornecendo uma estrutura na qual os objetivos da organização são definidos e o desempenho é monitorado. Nota-se que a Governança Corporativa não se restringe a garantir o retorno aos investidores, mas se propõe a definir os objetivos da organização e prezar pelo desempenho corporativo.

Para o Instituto Brasileiro de Governança Corporativa (IBGC, 2004), na concepção da teoria Econômica Tradicional, a Governança Corporativa surge para suplantar os problemas entre agente e principal, presentes a partir da separação entre propriedade e controle nas organizações. Nessa linha, a Comissão de Valores Mobiliários (CVM, 2002) descreve a Governança Corporativa como um conjunto de práticas que busca, além de proteger as partes interessadas, aperfeiçoar o desempenho da companhia e facilitar o acesso ao capital. 
O surgimento da Governança Corporativa está associado ao controle e monitoramento dos negócios, auxiliando na identificação e solução de possíveis problemas de agência e permitindo que a empresa possua melhores condições de acesso ao mercado de capitais. De acordo com Guerra (2009), a implantação do modelo de Governança Corporativa foi demandada ao setor privado após os escândalos empresariais. Cadburry e Millstein (2005) destacam que os episódios proporcionaram a instituição de novas normas, como a Lei Sarbannes-Oxley (SOX), em 2002, que converteram em obrigatórias algumas práticas tidas como voluntárias para as companhias com ações negociadas na Bolsa de Nova Iorque. Essas alterações normativas, de acordo com Becht, Bolton e Röell (2005), tinham como finalidade reestabelecer a confiança dos investidores nos relatórios financeiros das empresas.

\section{Conselho de Administração e Teoria da Dependência de Recursos}

O Conselho de Administração é um dos principais mecanismos de Governança Corporativa (Shleifer \& Vishny, 1997). Sua importância respalda-se na adoção de ações pela transparência, integridade e prestação de contas da empresa e sua gestão, incluindo supervisão da diretoria (Terra \& Lima, 2006). Sob a perspectiva da teoria da Agência, o Conselho de Administração é fundamental na resolução de conflitos de interesses próprios da gestão organizacional, constituindo um importante mecanismo interno para a estrutura de Governança das grandes corporações (Hermalin \& Weisbach, 2001). Williamson (1984) descreve que a autoridade legal concedida ao conselho de administração para contratar, demitir e compensar os gestores é uma das características que transformam o conselho em um elemento essencial da Governança Corporativa.

A atuação do Conselho de Administração tem se destacado por minimizar problemas advindos de uma organização de capital pulverizado. Nesse tipo de organização, os investidores adotam uma posição passiva como acionistas, deixando aos executivos o papel de definir e executar as estratégias corporativas. A passividade dos investidores abre espaço para inúmeros casos de oportunismo, quando os executivos atuam segundo seus próprios interesses (Fontes Filho \& Leal, 2012).

Em países como o Japão e a Alemanha, caracterizados pela concentração da propriedade em torno de grupos empresariais e bancos, a atuação do conselho tem-se direcionado a atender às expectativas de grupos de interesse e demandas da sociedade (Fontes Filho \& Leal, 2012). Portanto, em mercados de propriedades concentradas, observa-se que o conselho de administração tem se destacado por exercer outro importante papel: o papel de ligação entre as organizações.

Cabe observar que a concentração de propriedade nas corporações brasileiras também alcança patamares altíssimos. De acordo com Clemente, Taffarel e Silva (2012) apenas oito setores correspondem a $85 \%$ do volume de negociação das ações, sendo que 24 companhias representam 72,30\% desse volume. Embora a teoria da Agência tenha se mostrado essencial para o entendimento do papel do controle do Conselho de Administração, Eisenhardt (1989) descreve que somente ela não é suficiente para compreender a complexidade das organizações. De acordo com Huse (2007), por muito tempo a teoria da Agência vem sendo considerada uma "autoridade divina" nos debates sobre Governança Corporativa. Todavia, suas atribuições vêm sendo fonte de questionamento por não considerar as características sociais dos indivíduos. Nesse contexto, a necessidade de outra abordagem teórica torna-se importante para compreensão de alguns fenômenos que ocorrem no cenário organizacional.

Em face dessa discussão, vários estudos (Boyd, 1990; Pearce \& Zahra, 1992; Daily \& Dalton, 1994; Gales \& Kensen, 1994 Hillman \& Dalziel, 2003) têm utilizado a Teoria da administração como fonte de recursos essenciais para a organização. 
A teoria da Dependência de Recursos propõe que o conselho de administração é um mecanismo de gestão de recursos externos (Pfeffer \& Salancik, 1978), agindo como redutor de incertezas (Pfeffer, 1972) e proporcionando a diminuição do custo de transação (Williamson, 1984). O papel dos conselheiros, na visão da teoria da Dependência de Recursos diverge do papel de agência, embora conselheiros possam desempenhar ambos os papéis de forma simultânea (Johnson et. al., 1996). Sob a ótica da dependência de recursos, diretores servem de conexões entre a firma e o ambiente corporativo, minimizando as incertezas dos fatores contingenciais (Hillman, Cannella \& Paetzold, 2000).

Segundo Zald (1969), a premissa subjacente à teoria da Dependência de Recursos fundamenta-se na ideia de que as organizações, por mais independentes que possam parecer, não podem desconsiderar a relevância de recursos externos para seu desenvolvimento. Em outras palavras, por mais autônoma que seja a organização, ela sempre necessitará de recursos que não estão em seu poder. Para Thompson e McEwen (1958), o acesso a recursos externos torna-se facilitado quando corporações estabelecem ligações com outras firmas, trabalhando em prol de objetivos comuns.

Para sobreviver, as organizações precisam lidar de forma eficiente com as incertezas (Pfeffer \& Salancik, 1978). Tais incertezas restringem o acesso e o controle das organizações em relação a recursos e escolhas estratégicas, comprometendo seu desempenho. Para minimizar o nível de incerteza, as organizações utilizam o conselho de administração como mecanismo de acesso a outras corporações, trazendo recursos como informação, habilidades, acesso a fontes de financiamento e legitimação (Gales \& Kesner, 1994). A consolidação dessas conexões se dá pela inserção de profissionais em comum nos conselhos de administração, ou seja, um mesmo profissional atuando no conselho de duas empresas.

De acordo com Judge e Zeithaml (1992), o envolvimento do Conselho de Administração nas decisões estratégicas é um processo complexo. Mudanças no ambiente normalmente são associadas a transformações nas estratégias corporativas (Hillman, Cannella \& Paetzold, 2000). Essas mudanças, em parte, podem ser explicadas pela existência de fatores contingenciais inerentes à organização.

Os fatores contingenciais podem influenciar o ambiente organizacional, tanto interna como externamente. Para Mintzberg (1983), fatores de origem externa, como mercado, clientes, governo, sociedade e concorrentes, são mais importantes, pois não podem ser diretamente controlados pela organização. Tais fatores dificultam a aquisição de recursos pela empresa e aumentam o nível de incerteza do mercado (Hung, 1998). Sob a influência dos fatores contingenciais de origem externa, o conselho de administração tem um importante papel no acesso aos recursos críticos à empresa, como é reconhecido na teoria da Dependência de Recursos (Pfeffer, 1972). Segundo essa ótica, as empresas dependem umas das outras para conquistar recursos valiosos, estabelecendo ligações entre si na tentativa de regular sua interdependência (Hung, 1998). Quando as ligações ocorrerem por meio do conselho de administração, surge o fenômeno denominado Board Interlocking.

\section{Caracterização do Board Interlocking}

As expressões Board Interlocking (Santos \& Silveira, 2007; Bizjak, Lemmon \& Whitby, 2009; Silva, 2010; Connelly \& Slyke 2012), interlocking directorship (Zajac, 1988; Hung, 1998; Au; Peng \& Wang, 2000), board network (Battiston, Weisbuch \& Bonabeau, 2003; Kim, 2005), director interlocks (Hauschild \& Beckman, 1998) e interlocking directorates (Dooley, 1969; Ornstein, 1982) têm sido utilizadas na literatura financeira para definir ligações entre empresas por meio de Conselho de Administração.

Board Interlocking ocorre quando um profissional atua simultaneamente no Conselho de Administração de duas empresas. Em outras palavras, trata-se de uma relação social criada entre duas empresas por meio da inclusão de um profissional em comum nos conselhos de administração (Fich \& White, 2005). Esse profissional fornece acesso a importantes recursos indispensáveis para a empresa (Hung, 1998).

Nos EUA, é comum a ocorrência de participações de conselheiros e executivos em mais de uma empresa (Fontes Filho \& Leal, 2012). Na década de 30, Dooley (1969) constatava que, das 250 maiores organizações americanas, $90 \%$ possuíam, no mínimo, um conselheiro trabalhando em outra empresa. 
Davis (1991) descreve que a presença de laços entre as organizações americanas era evidente na década de 80 . Os conselheiros das grandes corporações participavam, em média, do conselho de administração de outras sete grandes corporações, formando redes de mais de quarenta empresas.

No Canadá, a presença de Board Interlocking é um fenômeno comum entre as maiores corporações. Ornstein (1982) constatou que, no período de 1946 a 1977, as 100 maiores empresas canadenses apresentaram aproximadamente, 1.600 laços em cada período. Au, Peng e Wang (2000) identificaram Board Interlocking em aproximadamente $61 \%$ das 200 maiores empresas de Hong Kong em 1997, percentual pouco abaixo do demonstrado pela Inglaterra (69\%) e pelos Estados Unidos (64\%), para o mesmo período. Cox e Rogerson (1985) investigaram as 115 maiores organizações da África do Sul, 110 indústrias e 5 bancos evidenciaram que, aproximadamente, $50 \%$ possuem um conselheiro atuando em mais de uma corporação.

Santos e Silveira (2007) investigaram 320 empresas com liquidez no mercado de capitais brasileiro, nos anos de 2003 e 2005. Os resultados indicaram percentuais de 74\% (2003) e 68,8\% (2005) de Board Interlocking. Também, em 2005, cerca de 50\% dos profissionais que atuavam na Presidência do conselho participavam do conselho de outra empresa, simultaneamente. Silva (2010) estudou 452 empresas, no período de 1997 a 2007, e constatou que, em média, 60\% dos conselheiros estavam conectados a 7 (sete) companhias.

Os principais estudos sobre Board Interlocking fundamentam-se na teoria da Dependência de Recursos para explicar as razões das conexões criadas entre as empresas (Hillman, Cannella \& Paetzold, 2000). Pfeffer e Salancik (1978) descrevem que, quando a organização nomeia um profissional para integrar seu conselho de administração, espera-se que esse conselheiro propicie recursos para ajudar a empresa a se desenvolver. Sugere também que a adoção do Board Interlocking pode proporcionar vários benefícios para a entidade, como: i) fornecimento de recursos específicos; ii) auxílio na obtenção de apoio de importantes elementos externos à empresa; iii) legitimação; e iv) criação de um canal de comunicação entre as organizações.

Hillman, Cannella e Paetzold (2000) explicam que Board Interlocking é uma substancial fonte de recursos externos e que as empresas buscam inserir em seus conselhos profissionais que desempenham funções gerenciais em outras organizações, com o propósito de aumentar as fontes de financiamento. Esses profissionais agregam valiosos recursos, uma vez que fornecem informações e auxiliam no processo de tomada de decisão da empresa. A premissa básica da teoria da Dependência de Recursos sugere que o fornecimento de recursos por meio do Board Interlocking está diretamente relacionado ao desempenho da empresa (Hillman, Cannella \& Paetzold, 2000).

Board Interlocking é benéfico para as empresas conquistarem apoio de importantes elementos externos. A inclusão de profissionais representantes de grupos sociais ou movimentos pode auxiliar a organização a evitar ações conflitantes com tais grupos (Selznick, 1965). Outro benefício conquistado quando empresas estabelecem conexões entre si por meio de seus conselheiros é a legitimação. Para Schoorman, Bazerman e Atkin (1981), Hillman, Cannella e Paetzold (2000) e Barringer e Harrison (2000), é interessante a organização adicionar profissionais com reconhecida experiência e conhecimento ao seu conselho. Essa atitude reflete uma boa imagem da empresa para o mercado. Por último, as empresas procuram adicionar ao conselho, profissionais ligados a organizações que dominam recursos escassos, obtendo, assim, facilidade de acesso. Pfeffer e Salancik (1978) destacam que as empresas incluem em seu conselho, profissionais pertencentes a instituições financeiras para, assim, conseguir acesso facilitado a linhas de crédito diferenciadas.

Nota-se, na literatura internacional, que são variadas as causas para a formação do Board Interlockig, como, por exemplo, a busca por apoio de grupos externos (Selznick, 1965); legitimação (Hillman, Cannella \& Paetzold, 2000); e facilidade a recursos escassos (Pfeffer \& Salancik, 1978). Porém, na literatura brasileira, ainda praticamente inexistem estudos sobre os fatores que determinam a existência de conexões corporativas. Assim, este artigo procura, por meio da análise das empresas que compõem o Ibovespa, lançar os primeiros questionamentos sobre essa prática no mercado de capitais brasileiro, identificando os seus principais fatores determinantes. 


\section{Metodologia}

O Índice Bovespa (Ibovespa) representa uma carteira teórica baseado no desempenho médio das cotações de ações de maior representatividade no mercado de capitais brasileiros. A inclusão do título no Ibovespa é condicionada a alguns requisitos: i) estar entre os títulos elegíveis que possuam um Índice de Negociabilidade (IN) superior a 85\%, levando em consideração as três últimas carteiras; ii) ter presença de $95 \%$ em pregões; iii) possuir participação maior ou igual a $0,1 \%$ do volume financeiro; e iv) não se classificar como "Penny Stock", ou seja, ativo cuja cotação seja inferior a R \$ 1,00 (um real) (BM\&FBOVESPA, 2015).

A carteira teórica do Ibovespa tem vigência quadrimestral, entrando em vigor na primeira segundafeira de cada período. No término de cada quadrimestre, a carteira é balanceada novamente para a constituição da nova carteira (BM\&FBOVESPA, 2015). Para o estudo, empregou-se a carteira correspondente ao período de setembro a dezembro de 2013, representada por 69 ações. Entre as ações identificadas, havia casos de uma mesma empresa apresentar na composição do índice, ações ordinárias e preferenciais, como os casos da: Petrobras, Eletrobras, Vale, Usiminas e Oi. Por isso, o número de empresas analisadas reduziu-se para 64 ações. Ademais, foram excluídas da amostra as instituições financeiras (6 empresas), com o propósito de não distorcer a análise, constituindo, assim, uma amostra por acessibilidade.

Este artigo abrange as empresas brasileiras que entraram na composição do Ibovespa no período de 2008 a 2014. A amostra compreende 58 empresas não financeiras distribuídas entre 14 setores de atividade, conforme a classificação do banco de dados Economática, como apresentado na Tabela 1.

Tabela 1

\section{Distribuição da amostra da pesquisa}

\begin{tabular}{clcc}
\hline & \multicolumn{1}{c}{ Setores } & Amostra & \% \\
\hline 1 & Alimentos e Bebidas & 4 & $6,90 \%$ \\
\hline 2 & Comércio & 6 & $10,34 \%$ \\
\hline 3 & Construção & 7 & $12,07 \%$ \\
\hline 4 & Energia Elétrica & 10 & $17,24 \%$ \\
\hline 5 & Mineração & 3 & $5,17 \%$ \\
\hline 6 & Outros & 9 & $15,52 \%$ \\
\hline 7 & Papel e Celulose & 3 & $5,17 \%$ \\
\hline 8 & Petróleo e Gás & 2 & $3,45 \%$ \\
\hline 9 & Química & 2 & $3,45 \%$ \\
\hline 10 & Siderurgia \& Metalurgia & 4 & $6,90 \%$ \\
\hline 11 & Software e Dados & 1 & $1,72 \%$ \\
\hline 12 & Telecomunicações & 3 & $5,17 \%$ \\
\hline 13 & Transporte Serviço & 3 & $5,17 \%$ \\
\hline 14 & Veículos e peças & 1 & $1,72 \%$ \\
\hline Total & & 58 & $100,00 \%$ \\
\hline
\end{tabular}

Fonte: dados do banco de dados Economática ${ }^{\circledR}$

A classificação por setor seguiu os critérios da Economática ${ }^{\oplus}$. Esse banco de dados classifica as empresas em 20 setores, dos quais 14 estão compreendidos na amostra. Destaca-se o setor de energia elétrica como o de maior participação na amostra, aproximadamente 17\%. Para identificação dos dados referentes aos conselhos de administração, utilizaram-se as informações contidas nos Formulários de Referência, disponibilizados no website da Bolsa de Valores de São Paulo (BM\&FBOVESPA). Tais informações possibilitaram a obtenção das variáveis e métricas empregadas na análise de redes sociais. Primeiramente, foram coletadas, para cada um dos 6 anos, as informações referentes aos conselheiros. Posteriormente, com o auxílio do software MS Excel, foram desenvolvidas matrizes quadradas, auxiliando na identificação das conexões entre empresas. Após a criação das matrizes, utilizaram-se os softwares Ucinet 6 e Net Miner 3.0 para obtenção das métricas de redes sociais. 


\section{Análise estrutural das redes}

Na Figura 1, apresentam-se as configurações de redes corporativas entre as empresas brasileiras pertencentes ao Índice Ibovespa, no período de 2009 a 2014.
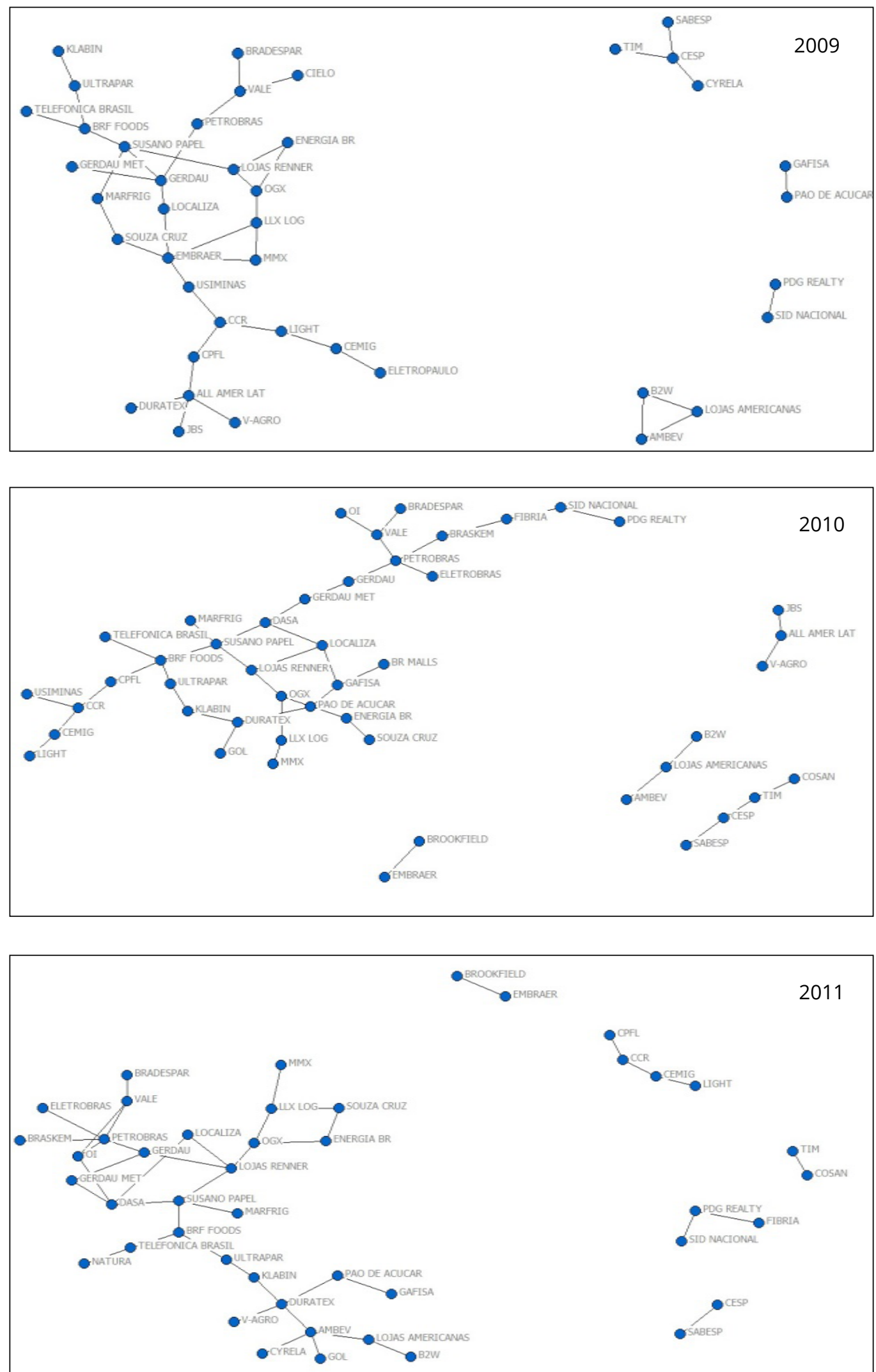

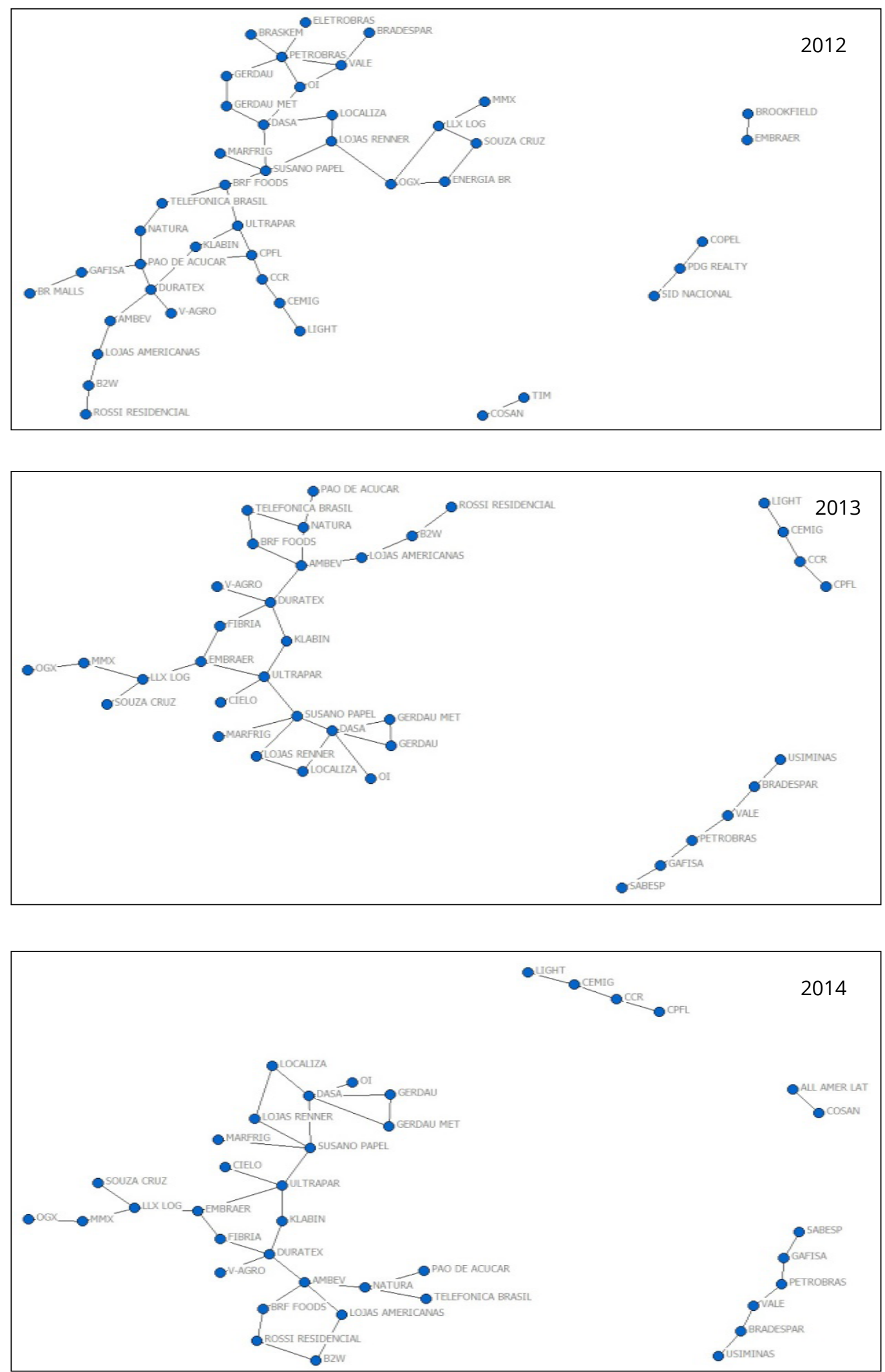

Figura 1. Configuração das ligações entre empresas do Ibovespa no período de 2009 a 2014 Fonte: elaborado pelos autores. 
A disposição das empresas da amostra no ano de 2009 mostra uma grande rede constituída por mais de $60 \%$ das empresas que constituem o Ibovespa, além de 4 ligações menores. Entre as empresas pertencentes à rede maior, a companhia Suzano S.A. possuiu 8 ligações diretas, ou seja, compartilha seus profissionais do conselho com as empresas BRF Foods, Gerdau, Lojas Renner, Marfrig, OGX, Localiza, Ultrapar e Gerdau Metalurgia.

A priori, notam-se algumas alterações na estrutura das ligações em relação a 2009. A rede formada pelas companhias Pão de Açúcar, Gafisa e BrMalls, que estavam isoladas em 2009, passaram a integrar a rede principal por meio do compartilhamento de conselheiro da empresa Pão de Açúcar com a Klabin e a Duratex. Situação similar ocorreu com a Siderúrgica Nacional e PDG Realty. As empresas Usiminas, CPFL, CCR, Cemig e Light desmembraram-se da rede principal para constituir uma rede menor. Essas alterações demonstram a dinâmica do ambiente corporativo e induz a pensar que, embora as ligações entre empresas pertencentes à rede principal apresentem-se mais consistentes, a substituição de conselheiros nas redes periféricas é uma característica comum.

A estrutura das redes apresentou alterações em comparação a 2010. Empresas, como Tim, Cosan, Cesp e Sabesp, que formavam uma rede de contatos, separaram-se constituindo duas pequenas redes; a primeira formada pelas empresas Tim e Cosan; e a segunda, pelas companhias Cesp e Sabesp. Essa segmentação pode estar associada à saída do ex-presidente do BNDES, Andrea Sandro Calabi, do Conselho de Administração da Tim, para assumir o cargo de secretário da Fazenda do Estado de São Paulo. Seu egresso da companhia rompeu os laços que a empresa possuía com a Cesp e Sabesp.

Com a saída do diretor de Mercados de Capitais do BNDES, Eduardo Rath Fingerl, do Conselho da Brasken, a Fibria desmembrou-se da rede principal e deu origem a uma nova rede com PDG Realty e Sid. Nacional. Por outro lado, empresas como a B2W, Lojas Americanas e Ambev passaram a constituir a rede principal por meio do compartilhamento de conselheiros com a Duratex e Gol. As empresas B2W, Lojas Americanas e Ambev fazem parte do grupo econômico da família Lemann. A conexão do grupo com as empresas Duratex e Gol deu-se pelo compartilhamento do ex-presidente mundial do Citibank Private Bank, Álvaro Antônio Cardoso de Souza. Para os analistas de mercado, a inclusão de Álvaro de Souza no Conselho de Administração agrega experiência e credibilidade para as organizações.

Observa-se que a rede principal absorveu algumas redes que se encontravam isoladas. Empresas, como Light, Cemig, CCR e CPFL, que formaram uma pequena rede em 2011, passaram a integrar a rede principal, dividindo conselheiros com as empresas Ultrapar e Pão de Açúcar. A ligação da empresa CPFL com a companhia Pão de Açúcar surgiu a partir da inserção da ex-presidente da Comissão de Valores Mobiliários (CVM), Maria Helena dos Santos Fernandes Santana no Conselho de ambas companhias. Entende-se que a presença dessa conselheira se deu, principalmente, em virtude de sua experiência no mercado de capitais.

Por outro lado, os laços criados entre CPFL e Ultrapar estão relacionados ao controle exercido por fundos de pensão dos funcionários do Banco do Brasil, essa premissa está fundamentada na presença do bancário Ivan de Souza Monteiro no Conselho de Administração das duas empresas. Essa ligação induz a pensar que empresas tendem a incluir profissionais no conselho de companhias ligadas aos fundos de pensão como forma de monitorar as decisões tomadas pelos executivos dessas organizações. Na Tabela 2, evidenciam-se a as ligações entre as organizações no período analisado. 
Tabela 2

Relação entre empresas e formação do Board Interlocking

\begin{tabular}{lcc}
\hline & Frequência Absoluta & Frequência Relativa \\
\hline Não apresentaram & 6 & $10,34 \%$ \\
\hline Apresentaram em um ano & 2 & $3,45 \%$ \\
\hline Apresentaram em dois anos & 3 & $5,17 \%$ \\
\hline Apresentaram em três anos & 8 & $13,79 \%$ \\
\hline Apresentaram em quatro anos & 8 & $13,79 \%$ \\
\hline Apresentaram em cinco anos & 3 & $5,17 \%$ \\
\hline Apresentaram em seis anos & 28 & $48,28 \%$ \\
\hline Total & 58 & $100,00 \%$ \\
\hline
\end{tabular}

Fonte: dados da pesquisa.

Nota-se que 28 (vinte e oito) das 58 (cinquenta e oito) empresas analisadas, quase metade, mantiveram Board Interlocking por todo o período de seis anos. Apenas seis empresas, cerca de 10\%, não apresentaram Board Interlocking no período. Destaca-se que cinco dessas seis empresas apresentam pulverização do capital. Isso sugere que empresas com essa característica tendem a não estabelecer ligações e a manter seus conselhos independentes de outras. Nessa linha, a larga incidência de Board Interlocking entre as empresas listadas na BM\&FBOVESPA estaria associada à presença de grupos econômicos fortemente majoritários, ao controle governamental e à atuação dos fundos de pensão.

Na Figura 2, apresentam-se as empresas cujos laços permaneceram estáveis durante o período de 2009 a 2014.

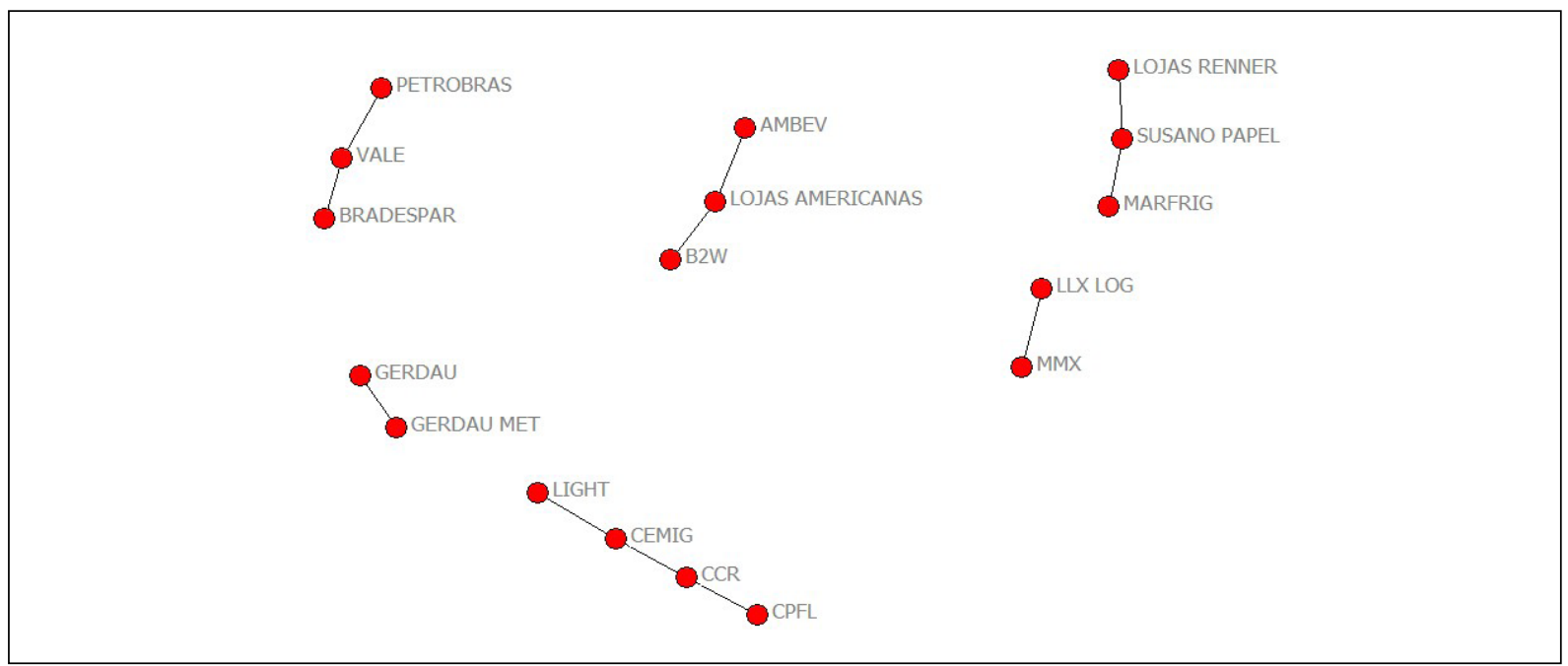

Figura 2. Laços permanentes de 2009 a 2014.

Fonte: elaborado pelos autores. 
Verifica-se a formação de seis redes permanentes entre as empresas analisadas. As redes constituídas pelas empresas Gerdau e Gerdau Met e MMX e LLX (Prumo Logística) representam a formação de grupos econômicos. A rede formada pelas empresas Petrobras, Vale e Bradespar caracteriza a instituição de ligações sob a perspectiva de controles governamentais. Nota-se, também, a existência de ligações governamentais indiretas, em que, por meio do BNDES o governo exerce sua influência na cúpula de controle das companhias.

Constata-se, também, que a existência de fundos de pensão pode ser determinante para a constituição de laços entre conselhos de administração. A Previ (Banco do Brasil), Petros (Petrobras) e Funcef (Caixa Econômica Federal) possuem participação em várias empresas de capital aberto. Assim, a inclusão de conselheiros em comum entre as empresas tende a auxiliar no monitoramento das decisões tomadas pela companhia investida. Por último, observou-se que as redes são formadas pela presença de profissionais com conhecimento e expertise de mercado, pois a inserção de pessoas como essas tende a favorecer a imagem da organização frente aos investidores.

Portanto, nota-se que a presença do Board Interlocking é uma característica comum entre as empresas integrantes do Ibovespa. De acordo com os resultados obtidos, essa característica pode estar associada aos seguintes fatores:

I) existência de grupos econômicos: ocorre quando profissionais atuam simultaneamente no conselho de empresas pertencente ao mesmo grupo, agindo como fonte de informação entre controladora e subsidiária. Fato esse observado entre as empresas OGX, MMX e LLX, Gerdau e Gerdau Metalúrgica e Ambev, Lojas Americanas e B2W;

II) controle governamental: verifica-se quando a União, por meio de suas entidades, exerce influência no controle de determinadas companhias. O BNDES Participações S.A. é um exemplo, sua representativa participação em empresas como Petrobras, Vale, Suzano, Klabin, Gerdau, CPFL, entre outras, permite a inclusão de profissionais no conselho das respectivas companhias;

III) existência de fundos de pensão: acontece quando empresas criam carteiras de investimentos com a finalidade de auxiliar na aposentadoria de seus funcionários. O Banco do Brasil é uma empresa que realiza esse tipo de investimento. Por isso, a inclusão de profissionais no conselho de empresas com ações pertencentes ao fundo de pensão é essencial para o controle das decisões dos gestores; $\mathrm{e}$

IV) inserção de profissionais com reconhecida experiência de mercado: normalmente, empresas buscam incluir profissionais com grande conhecimento de mercado em seus conselhos para que suas experiências auxiliem no processo de tomada de decisão. Profissionais como, Maria Helena dos Santos Fernandes Santana e Álvaro Antônio Cardoso de Souza, por exemplo, são muito requisitados pelas companhias, uma vez que suas bagagens de conhecimento são importantes fontes de informação no momento de adotar determinadas práticas corporativas.

Destaca-se ainda que grande parte das alterações na configuração das redes corporativas ocorre em virtude de ligações entre empresas por meio de profissionais com reconhecida experiência. Essas ligações tendem a ser mais inconstantes, uma vez que tais profissionais são muito requisitados pelas empresas. Por outro lado, laços associados aos demais fatores, como, grupos econômicos, controle governamental e fundos de pensão, tendem a ser mais estáveis, pois correspondem a relações em longo prazo. 


\section{Conclusões}

A pesquisa tem como objetivo identificar os principais determinantes para a formação do Board Interlocking no mercado de capitais brasileiro. Para tanto, foram utilizadas como amostra 58 empresas brasileiras pertencentes ao Ibovespa. O estudo contribuiu para o entendimento de aspectos organizacionais que influenciam a formação de laços corporativos nas organizações, especificamente, quando se considera a existência do Board Interlocking.

A análise exploratória foi realizada utilizando como base os dados referentes ao Conselho de Administração nos Formulários de Referência, disponibilizados no website da Bolsa de Valores de São Paulo (BM\&FBOVESPA). Tais informações foram coletadas para cada um dos 6 anos e posteriormente convertidas em matrizes quadráticas, para que assim pudessem ser identificadas as conexões entre empresas.

A partir da identificação das conexões entre as empresas, os resultados encontrados demostram que a presença do Board Interlocking é comum para as empresas pertencentes ao Ibovespa e normalmente estão associadas a quatro fatores: (1) formação de grupo econômico; (2) controle governamental; (3) formação de fundos de pensão; e (4) presença de profissionais com reconhecida experiência de mercado. Os três primeiros fatores originam ligações mais duradouras e dificilmente tais conexões são rompidas. Por outro lado, as ligações realizadas por meio de profissionais com experiência de mercado tendem a ser mais instáveis devido ao fato da sua presença desses profissionais ser muito requisitada no conselho de diferentes companhias.

Os resultados convergem parcialmente com o estudo de Dooley (1969) no que se refere ao favorecimento da formação do Board Interlocking pela existência de grupos econômicos, com os estudos de Schoorman, Bazerman e Atkin (1981), Hillman, Cannella e Paetzold (2000) e Barringer e Harrison (2000), no que se refere à inclusão de um profissional no Conselho de Administração da empresa com conhecimento e expertise. Essa atitude reflete uma boa imagem da empresa para o mercado.

Acredita-se que, na vertente da teoria da Dependência de Recursos, as conexões estabelecidas por meio do Board Interlocking são fundamentais para facilitar a obtenção de importantes recursos financeiros para a empresa, mas também podem tornar-se canais para disseminação de práticas corporativas, como o gerenciamento de resultado, assimetria informacional e perda da qualidade informacional. 


\section{Referências}

Au, K., Peng, M. W. \& Wang, D. (2000). Interlocking directorates, firm strategies and performance in Hong Kong: Towards a research agenda. Asia Pacific Journal of Management, 17(1), pp. 29-47. doi: 10.1023/A:1015432819596

Barney, J. B. \& Hesterly, W. (2004). Economia das organizações: entendendo a relação entre as organizações e a análise econômica. In: Clegg, S. R., Handy, C. \& Nord, W. R. (org.). Handbook de estudos organizacionais: ação e análise organizacionais. São Paulo: Atlas.

Barringer, B. R. \& Harrison, J. S. (2000). Walking a tightrope: creating value through interorganizational relationships. Journal of Management, 26(3), pp. 367-403. doi:10.1016/S0149-2063(00)00046-5

Battiston, S. G., Weisbuch \& Bonabeau E. (2003). Decision spread in the corporate board network. Advances in Complex Sysytems, 6, pp 631-644. doi: http://dx.doi.org/10.1142/S0219525903001109

Becht, M., Bolton, P. \& Röell, A. A. (2005). Corporate governance and control. European Corporate Governance Institute - ECGI Finance Working Paper n. 02/2002. (October, 2002). Updated: August, 2005. doi: http://dx.doi.org/10.2139/ssrn.343461

Berle, A. \& Means, G. (1932). The modern corporation and private property. New York: Macmillan.

Bizjak, J. M., Lemmon, M. L. \& Whitby, R. J. (2009) Option Backdating and Board Interlocks. Review of Financial Studies, 22(11), pp. 4821-4847. doi:10.1093/rfs/hhn120

BM\&FBOVESPA (2015). Metodologia do Índice Bovespa. São Paulo. Recuperado em 9 de março, 2016 de $<$ http://www.bmfbovespa.com.br/Indices/download/IBOV-Metodologia-pt-br.pdf >.

Boyd, B. (1990). Corporate linkages and organizational environment: A test oi the resource dependence model. Strategic Management Journal, 11(6), pp. 419-430. doi: 10.1002/smj.4250110602.

Cadbury, A. \& Millstein, I. M. (2005). The new agenda for ICGN. International Corporate Governance Discussion Paper. $\mathrm{n} .1$ for the ICGN $10^{\text {th }}$ Anniversary Conference London.

Carlsson, R. (2001). Ownership and Value Creation: strategic corporate governance in the new economy. New York: John Wiley \& Sons.

Camilo, S. P. O., Marcon, R. \& Bandeira-de-Mello, R. (2012). Conexões políticas e desempenho: um estudo das firmas listadas na BM\&FBovespa. Revista de Administração Contemporânea. 16(6), pp. 784805. doi: http://dx.doi.org/10.1590/S1415-65552012000600003

Clemente, A.; Taffarel, M. \& Silva, W. V. (2012). The Brazilian common stock market reaction to corporations' performance. International Journal of Accounting, Auditing and Performance Evaluation. 8(4), pp. 336-354. doi: http://dx.doi.org/10.1504/IJAAPE.2012.050010

Comissão de Valores Mobiliários (2002). Recomendações da CVM sobre Governança Corporativa. São Paulo: CVM.

Connelly, B. L \& Slyke, E. J. V. (2012). The power and peril of board interlocks. Organizational Performance, 55(5), pp. 403-408. doi:10.1016/j.bushor.2012.03.006

Copeland, T., Weston, F. \& Shastri, K. (2005). Financial theory and corporative policy. Boston: Pearson Addison Wesley.

Cox, B. A. \& Rogerson, C. M. (1985). The corporate power elite in South Africa: interlocking directorships among large enterprises. Political Geography Quarterly, 4(3), pp. 219-234. doi:10.1016/02609827(85)90012-6

Daily, C. M. \& D. R. Dalton (1994). Corporate Governance in the Small Firm: Prescriptions for CEOS and Directors, Journal of Small Business Strategy, 5(1), pp. 57-68. 
Davis, G. F. (1991). Agents without principles? the spread of the poison pill through the intercoporate network. Administrative Science Quarterly, 36(4), pp. 583-613. doi: 10.2307/2393275

Dooley, P. C. (1969). The interlocking directorate. American Economic Review, 59(3), pp. 314-323.

Eisenhardt, K. M. (1989). Agency theory: an assessment and review. The Academy of Management Review. 14(1), pp. 57-74.

Fama. E. \& Jensen, M. (1983). Separation of ownership and control. Journal of Law and Economics, 26(2), PP. 301-325.

Fich, E. M. \& White, L. J. (2005). Why do CEOs reciprocally sit on each other's boards? Journal of Corporate Finance, 11, pp. 175-195. doi: http://dx.doi.org/10.2139/ssrn.249975

Fontes Filho, J. R. \& Leal, R. P. C. (2012). Governança corporativa: discussões sobre os conselhos em empresas no Brasil. São Paulo: Saint Paul.

Gales, L. \& Kesner, I. (1994). An analysis of board of director size and composition in bankrupt organizations. Journal of Business Research, 30(3), pp. 271-282. doi: 10.1016/0148-2963(94)90057-4

Guerra, S. (2009). Os papeis do Conselho de Administração em empresas listadas no Brasil. Dissertação de Mestrado em Administração, Universidade de São Paulo, São Paulo, SP, Brasil.

Hendriksen, E. S. \& Van Breda, M. F. (2007). Teoria da contabilidade. São Paulo: Atlas.

Haunschild, P. R. \& Beckman, C. M. (1998). When do interlocks matter? alternate sources of information and interlock influence. Administrative Science Quarterly, 43(4), pp. 815-844. doi: 10.2307/2393617

Hermalin, B. \& Weisbach, M. (2001). Board of directors as an endogenously determined institution: A survey of the economic literature. In: NBER [Working Paper n. 8161], Cambridge, Massachusetts.

Hillman, A., Cannella. A, \& Paetzold. R. (2000). The resource dependence role of corporate directors: Strategic adaptation of board composition in response to environmental change. Journal of Management Studies. 37(2), pp. 235-256. doi: 10.1111/1467-6486.00179

Hillman, A. J. \& Dalziel, T. (2003). Boards of directors and firm performance: integrating agency and resource dependence perspectives. Academy of Management Review, 28(3), pp. 383-396. doi:10.5465/ AMR.2003.1019672

Hung, H. (1998). A typology of the theories of the roles of governing boards. Scholarly Research and Theory Papers, 6(2), pp. 101-111.

Huse, M. (2007). Boards, governance and value creation. Cambridge: Cambridge University Press.

Instituto Brasileiro de Governança Corporativa. (2004). Código das melhores práticas de governança corporativa. $3^{\text {a }}$ ed. São Paulo: IBCG.

Iudicibus, S. \& Lopes, A. B. (2004). Teoria avançada da contabilidade. São Paulo: Atlas.

Jensen, M. C. \& Meckling, W. H. (1976). Theory of the firm: managerial behavior, agency costs and ownership structure. Journal of Financial Economics. 3(4), pp. 305-360. doi:10.1016/0304-405X(76)90026-X

Johnson. J., Daily, C, \& Ellstrand, A. (1996). Boards of directors: A review and research agenda. Journal of Management, 22(3), pp. 409-438. doi:10.1016/S0149-2063(96)90031-8

Judge, W. Q. \& Zeithaml, C. P. (1992). Institutional and strategic choice perspectives on board involvement in the strategic decision process. Academy of Management Journal. 35(4), pp. 758-794. doi: $10.2307 / 256315$

Kim, Y. (2005). Board network characteristics and firm performance in Korea. Corporative Governance, 13(6), pp. 800-808. doi: 10.1111/j.1467-8683.2005.00471.x 
Knowles, J. C. (1973). The rockfeller financial group. Andover Mass: Warner Modular Publications.

Lambert, R. A. (2001). Contracting theory and accounting. Journal of Accounting and Economics. 32(1-3), pp. 3-87. doi: http://dx.doi.org/10.1016/S0165-4101(01)00037-4

Mintzberg, H. (1983). Power in and around organization. Englewoods: Prentice-Hall.

Okimura, R. T. (2003). Estrutura de propriedade, governança corporativa, valor e desempenho das empresas no Brasil. Dissertação de Mestrado em Administração. Universidade de São Paulo, de São Paulo, SP, Brasil..

Organisation for Economic Co-operation and Development. (2004). Principles of Corporate Governance. Paris: OECD.

Ornstein, M. D. (1982). Interlocking directorates in Canada: evidence from replacement patterns. Social Networks, 4(1), pp. 3-25. doi:10.1016/0378-8733(82)90011-9

Pearce, J. A., (1983). The relationship of internal versus external orientations to financial measures of strategic performance. Strategic Management Journal, 4(4), pp. 297-306. doi: 10.1002/smj.4250040402

Pearce, J.A. \& Zahra, S.A. (1992). Board composition from a strategic contingency perspective. The Journal of Management Studies, 29(4), pp. 411-439. doi: 10.1111/j.1467-6486.1992.tb00672.x

Pfeffer, J. (1972). Size and composition of corporate boards of directors: The organization and its environment. Administrative Science Quarterly, 17(2), pp. 218-228. doi: 10.2307/2393956

Pfeffer, J. \& Salancik, G. R. (1978). The external control of organizations: a resource dependence perspective. New York: Harper \& Row.

Pratt, J.W. \& R.J. Zeckhauser (1985), Principals and Agents: The Structure of Business, Harvard Business School Press: Boston.

Ross, S. A. (1973). The economic theory of agency: the principal's problem. The American Economic Review. 63(2), pp. 134-139.

Santos, R. L. \& Silveira, A. D. M. (2007) Board Interlocking no Brasil: a participação de conselheiros em múltiplas companhias e seu efeito sobre o valor da empresa. Revista Brasileira de Finanças. São Paulo, 5(2), pp. 125-163.

Schoorman, F. D., Bazerman, M. H. \& Atkin, R. S. (1981). Interlocking directorates: a strategy for reducing environmental uncertainty. Academy of Management Review, 6(2), pp. 243-251. doi: 10.2307/257880

Segatto-Mendes, A. P. (2001). Teoria da agência aplicada à análise de relações entre os participantes dos processos de cooperação tecnológica universidade-empresa. Tese de Doutorado em Administração. Universidade de São Paulo, São Paulo, SP, Brasil.

Selznick, P. (1965). TVA and the Grass Roots. New York: Harper and Row.

Shleifer, A. \& Vishny, R. (1997). A survey of corporate governance. Journal of Finance, 52(2), pp. 737-783. doi: 10.1111/j.1540-6261.1997.tb04820.x

Silva, W. M. (2010). Board Interlocking, desempenho financeiro e valor das empresas brasileiras listadas na Bovespa: análise sob a ótica da teoria dos grafos e de redes sociais. Tese de Doutorado em Administração. Universidade de São Paulo, São Paulo, SP, Brasil..

Silveira, A. M., Barros, L. A. B. C \& Famá, R.(2003). Estrutura de governança e valor das companhias abertas brasileiras. Revista de Administração de Empresas, 43(3), pp. 50-64. http://dx.doi.org/10.1590/ S0034-75902003000300005

Smith, A. (1976). The Wealth of Nations. The University of Chicago press.

Spence, M. \& Zeckhauser, R. (1971). Insurance, information and individual action. American Economic Review, 61(2), pp. 380-387. doi: 10.1016/B978-0-12-214850-7.50027-9 
Terra, P. R. S. \& Lima, J. B. N. (2006). Governança corporativa e a reação do mercado de capitais à divulgação das informações contábeis. Revista Contabilidade e Finanças. São Paulo, 17 (42), pp. 35-49. doi: http://dx.doi.org/10.1590/S1519-70772006000300004

Thompson, J. G., \& McEwen, W. J. (1958). Organization goals and environment: Goal setting as an interaction process. American Sociological Review. 23(1), pp. 23-31. doi: 10.2307/2088620

Williamson, O. E. (1984). The economic institutions of capitalism: firms, markets, relational contracting. Nova Iorque: Free Press.

Zajac, E. J. (1988). Interlocking directorates as an interorganizational strategy: a test of critical assumptions. The Academy of Management Journal, 31(2), pp. 428-438. doi: 10.2307/256558

Zald, M, (1969). The power and functions of boards of directors: A theoretical synthesis, American Journal of Sociology, 75(1), pp. 97-111. doi: 10.1086/224747. 